\title{
A Consideration Of IFRS Education And Acceptance From Culturally Diverse Backgrounds: A South African Perspective
}

Pieter W Buys, North-West University, South Africa

Danie Schutte, North-West University, South Africa

\begin{abstract}
Accountancy's double-entry bookkeeping system has spread throughout the world over the past 5 centuries. Within each country, local accountants have adopted accountancy practices to suit their unique environment. In the modern global business environment, this uniqueness makes crossborder financial statement comparisons difficult. A key objective of a globally acceptable set of accounting standards (such as IFRS), is to enhance such trans-national comparisons of corporate performances. However, research revealed that the influence of cultural backgrounds is a key contributing factor influencing accounting practices. It is evident that culture is a key concomitant of accounting development, including accounting education. Two globally recognized authors on the importance of culture in the work environment, Hofstede and Gray, developed cultural dimensions to gauge the cultural impact in a business environment. The primary objective of this research was to consider the impact of different cultural backgrounds, as measured by Hofstede and Gray on prospective accountants in South Africa, as an early adopter of IFRS. The results of the study suggest that culture will play an important role in accounting education and acceptance in the culturally diverse South African context.
\end{abstract}

Keywords: Accounting; Cultural Diversity; GAAP; IFRS

\section{INTRODUCTION}

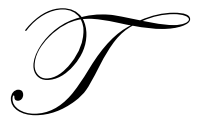

he globalization of the modern business environment and the wide acceptance of International Financial Reporting Standards (IFRS) mean that accounting practices are no longer constrained by national borders. Notwithstanding, the potential impact of differences in accounting techniques as used in different countries has been considered as early as 1965 by Mueller (1965:386) and Kollaritsch (1965:382). According to Tsakumis, Campbell and Doupnik (2009:34) it is envisioned that IFRS per the International Accounting Standards Board (IASB) and US GAAP per the Financial Accounting Standards Board (FASB) will eventually be incorporated into a single global set of accounting standards. However, the viability of this vision remains in question with research into the globalization efforts revealing many obstacles. Such obstacles includes national and regional differences in the interpretation and application of accounting principles and standards (Gujarathi, 2008:95; Lin \& Wang, 2001:263; Ernest \& Young, 2005:1), and varying levels of transparency in the IFRS adoption processes (Steffee, 2009:1). Furthermore, even though IFRS was due to be implemented in Canada by 2011, the Accounting Standards Oversight Council was asked to delay the implementation due to conflicting regulatory requirements, a lack of clarity in regulations, as well as educational and resource shortages (FEI Canada, 2007:1). IFRS education was also found to be lacking in the US where the first graduating class of accountants with a substantial knowledge of IFRS is only expected in 2015 (WEBCPA, 2009:1). Even though considerable effort has been expended in achieving uniformity, research indicated that countries may not even be in compliance with their current accounting standards, let alone be in a position to adopt global IFRS. Moreover, in cases where countries have embraced IFRS, such as South Africa, they experienced difficulties in preparing for the implementation and roll-out of IFRS. 
A key objective of the introduction of IFRS is to enable better comparison of financial performances across corporate and national boundaries. However, several observers warned about possible discrepancies in the process of adopting IFRS due to different views relating to the application of the standards and different cultural backgrounds of preparers of financial statements. Several authors, including Radebaugh (1997:46), HassabElnaby, Epps and Said (2003:273) and Garcia-Sordo and Baren (1999:314) argued that accounting is a product of its environment, and it is therefore expected that the accounting practices would be influenced by the local environment. As such the impact of differences in national cultures on the accounting function should not be ignored.

\section{RESEARCH PROBLEM AND OBJECTIVE}

In the South African context, the country boasts a wide range of diverse cultures and languages. During the 12th century its African ancestors started migrating southwards from the northern parts of the continent. They were followed by European settlers some three to four hundred years later. Currently South Africa has 11 official languages (Beukes, 2004:3), which, although it exclude several 'smaller' ethnic groupings, gives an indication of the diversity of the so-called 'Rainbow Nation'. The earlier mentioned research into accounting practices indicates that the consequence of cultural differences on the accounting environment cannot be denied. Since accounting education forms a key part of prospective accountants' accounting foundation, the primary research question of this article can therefore be formulated as follows:

P1: Should cultural differences be considered in the IFRS training of future accountants in the diverse South African context?

The primary objective of this article is therefore to research the cultural impact of prospective accountants' perceptions of IFRS and accounting in general, in the South African context. In order to address this aim, the article is set out in the following four key sections. The first section presents a theoretical framework of the cultural impact in a business, and then specifically an accounting context. The next section provides the empirical research results in the two phases of the project, which is then followed by a discussion of the results, including recommendations and finally a conclusion is provided.

\section{THEORETICAL FRAMEWORK}

Mueller, Gernon and Meek (1997:10) argued that all the things we learn, observe, feel, believe or prioritize, have a cultural dimension, while Marrero and Brinker (2007:16) state that humans assign specific values to their own reality. This results in certain principles that are considered as the norms and customs of a specific society. According to Perera (1989:43) culture is the most powerful environmental factor affecting the accounting system of a country. The common element in these definitions is the perception of culture as a programming of the mind. The impact of culture on various aspects of accounting has been investigated by a number of researchers. Historically, when considering accountancy practices, Jaggi (1975:76) found that cultural differences between developed and less developed countries resulted in differences in accounting disclosure, while Belkaoui (1990:5) stated that culture often prescribes the accounting environment and the cognitive functioning of individuals faced by accounting phenomena. Furthermore, from a standard-setting perspective, several researchers over the past three decades found that different cultures produce unique accounting structures shaped by cultural constraints (Xiao, Weetman \& Sun, 2004:193; Bloom \& Naciri, 1989:72; McKinnon, 1986:72-73; Violet, 1983:2). Finally, from the perspective of modern accounting education, Lindahl and Fanelli (2002:285) and Sullivan (2006:1-13) identified teaching challenges for prospective accountants with different cultural backgrounds.

In his earlier research Hofstede (1980:25) identified four measurable cultural dimensions; i) individualism versus collectivism, which is described as the relationship between the individual and the group, ii) power distance, which relates to social inequality including relationships with authority, iii) masculinity versus femininity, which relates to the social implications of being born male or female, and iv) uncertainty avoidance, which relates to the ability to deal with uncertainty, the control of aggression and the expression of emotion. Basing his accounting values on Hofstede's initial dimensions, Gray suggests that accounting values are derived from cultural dimensions, which in turn influences the accounting systems (Gray, 1988:8). To that effect, Gray identified four key accounting 
values; i) professionalism versus statutory control, referring to professional judgment and self-regulation in contrast to compliance with rigid legal requirements and legislative control, ii) uniformity versus flexibility, referring to the level of enforcement of standardized and consistent accounting practices, iii) conservatism versus optimism referring to a vigilant approach to accounting measurement as opposed to a more optimistic and risk-taking approach, and iv) secrecy versus transparency referring to confidentiality and the constraint of disclosure of information as opposed to a more transparent and publicly accountable approach. As a result of the interaction between Hofstede's cultural dimensions and Gray's accounting values, the following hypotheses were developed (Gray, 1988:8-11):

- The higher a ranking in terms of individualism and the lower the ranking in terms of uncertainty avoidance and power distance, the more likely it is to rank highly in terms of professionalism;

- $\quad$ The higher a ranking in terms of uncertainty avoidance and power distance and the lower the ranking in terms of individualism, the more likely it is to rank highly in terms of uniformity;

- $\quad$ The higher a ranking in terms of uncertainty avoidance and the lower the ranking in terms of individualism and masculinity, the more likely it is to rank highly in terms of conservatism; and

- The higher a ranking in terms of uncertainty avoidance and power distance and the lower the ranking in terms of individualism and masculinity, the more likely it is to rank highly in terms of secrecy.

Gray's hypotheses as stated above have been tested and validated by various empirical research projects, including Askary (2006:102), Olimid (2006:1), Willett (2002:31), Salter and Niswander (1995) and Sudarwan (1994:8).

\section{EMPIRICAL RESULTS}

\section{Research method}

The North-West University (NWU) in South Africa is a recently merged institution with three geographically dispersed campuses at Potchefstroom, Mafikeng and Vanderbijlpark. On January $1^{\text {st }}, 2004$ the University of the North-West based in Mafikeng, the Potchefstroom University for Christian Higher Education and the Vista University's Sebokeng Campus merged to create the NWU. With its merged status the NWU is made up of various cultures, backgrounds and belief systems. As the two culturally most diverse campuses of the NWU, this research project focused on the campuses in i) Potchefstroom (PTC), with participants from a predominantly white European background and ii) Mafikeng (MFK), with a predominantly black African population.

The target population for the empirical research was the accounting students from the final year accounting degree courses (Bachelor of Commerce degrees) of both campuses. The empirical research consisted of a questionnaire completed by the participants during a regular class period at both universities. Participation to the study was voluntary and the researchers were available during the sessions to clarify any uncertainties. The measurement instrument (questionnaire) used was the '1994 Value Survey Module' (Hofstede, 1994:1). The final response size consisted of 91 students at MFK and 118 students at PTC, which in both instances resulted in a response rate of more than $95 \%$ of the population. The empirical study was performed in two phases. In the first phase Hofstede's cultural dimensions were assigned to the participants in this study. In the second phase the results of Hofstede's cultural dimensions for accounting students were extended to Gray's accounting values.

\section{Phase 1: Hofstede's cultural dimensions}

The cultural dimensions of prospective accountants at the MFK and PTC campuses of the North-West University are set out in Table 1 below:

Table 1 - Index rating: Cultural dimensions

\begin{tabular}{|l|c|c|}
\hline \multicolumn{1}{|c|}{ Cultural dimensions } & MFK & PTC \\
\hline Individualism (IDV) & 59.51 & 20.97 \\
Power Distance (PDI) & 24.89 & 53.22 \\
Masculinity vs. Femininity (MAS) & 14.95 & 69.07 \\
Uncertainty Avoidance (UAI) & 88.57 & \\
\hline
\end{tabular}




\section{Individualism}

From the above information it is evident that individual rights, as measured by individualism, are more dominant at PTC (77.46) than at MFK (59.51). According to Garcia-Sordo and Baren (1999:2) a high score for this dimension focuses on the "I" whereas a low score focuses on the "we" of a group of individuals. Societies and cultures with a preference for individualism tend to also have a preference for a loosely-knit social framework. Participants from the PTC campus are therefore expected to take care of themselves and their immediate families only, whilst participants from the MFK campus expect their relatives to look after them in exchange for unconditional loyalty.

\section{Power Distance}

The results revealed that hierarchical orders or the fact that power is not distributed equally is marginally more acceptable at MFK (24.89) than at PTC (20.97). According to Gray (1988:7) cultures with lower power distances strive for power equalization and demand justification for power inequalities. Power inequalities should therefore more often be questioned at PTC whilst MFK may accept power inequalities more readily.

\section{Masculinity vs. Femininity}

A notable difference relating to masculinity versus femininity was revealed. According to Verma (2000:11) masculinity stands for qualities such as assertiveness and material success whereas femininity stands for qualities such as caring relationships and quality of life. Garcia-Sordo and Baren (1999:2) suggested that societies with high masculinity ratings value attributes such as income, recognition and advancement, whereas feminine dimensions include a preference for putting relationships with people before money, helping others, caring for the weak, quality of life and preservation of the environment. The results therefore suggest that attributes such as assertiveness and material success is significantly more important at PTC (53.22) than at MFK (14.95).

\section{Uncertainty Avoidance}

In this dimension the fundamental issue is how a society reacts to the fact that the future is unknown. According to Garcia-Sordo and Baren (1999:2) a high score for this dimension is indicative of a preference for extensive and rigid rules to decrease uncertainty. Cultures with a higher uncertainty orientation often punish deviation from norms to encourage conformity (Moustafa, Slaubaugh \& Wang, 2008:539). In essence, this dimension relates to the degree to which the members of society feel uncomfortable with uncertainty and ambiguity. Low uncertainty avoidance is an indication that members of a society feel in general secure and will not attempt to control the future through laws. In addition, different ideas and viewpoints will be more easily tolerated as well as willingness to take risk. A lower uncertainty avoidance ranking at PTC (69.07) is therefore an indication that individuals at PTC are relatively secure about the future and that different viewpoints are more easily tolerated than at MFK (88.57). The fact that uncertainty avoidance was assessed to be higher at MFK suggests that members of this grouping feel more anxious about the future which might result in measures to add security and avoid risk.

\section{Phase 2: Gray's accounting values}

The second phase consists of extending the cultural dimensions identified in the first phase to the accounting values of Gray (1988:5).

\section{Professionalism versus Statutory control / Uniformity versus Flexibility}

Gray's first hypothesis suggests that a higher ranking in terms of individualism (IDV) and a lower ranking in terms of uncertainty avoidance (UAI) and power distance (PDI) are indicative of a preference for professionalism, while his second hypothesis suggests that higher uncertainty avoidance (UAI) and power distance (PDI) rankings and a lower individualism (IDV) ranking is indicative of a preference for uniformity. The results of these two hypotheses in the context of this study are presented below in Figure 1. 


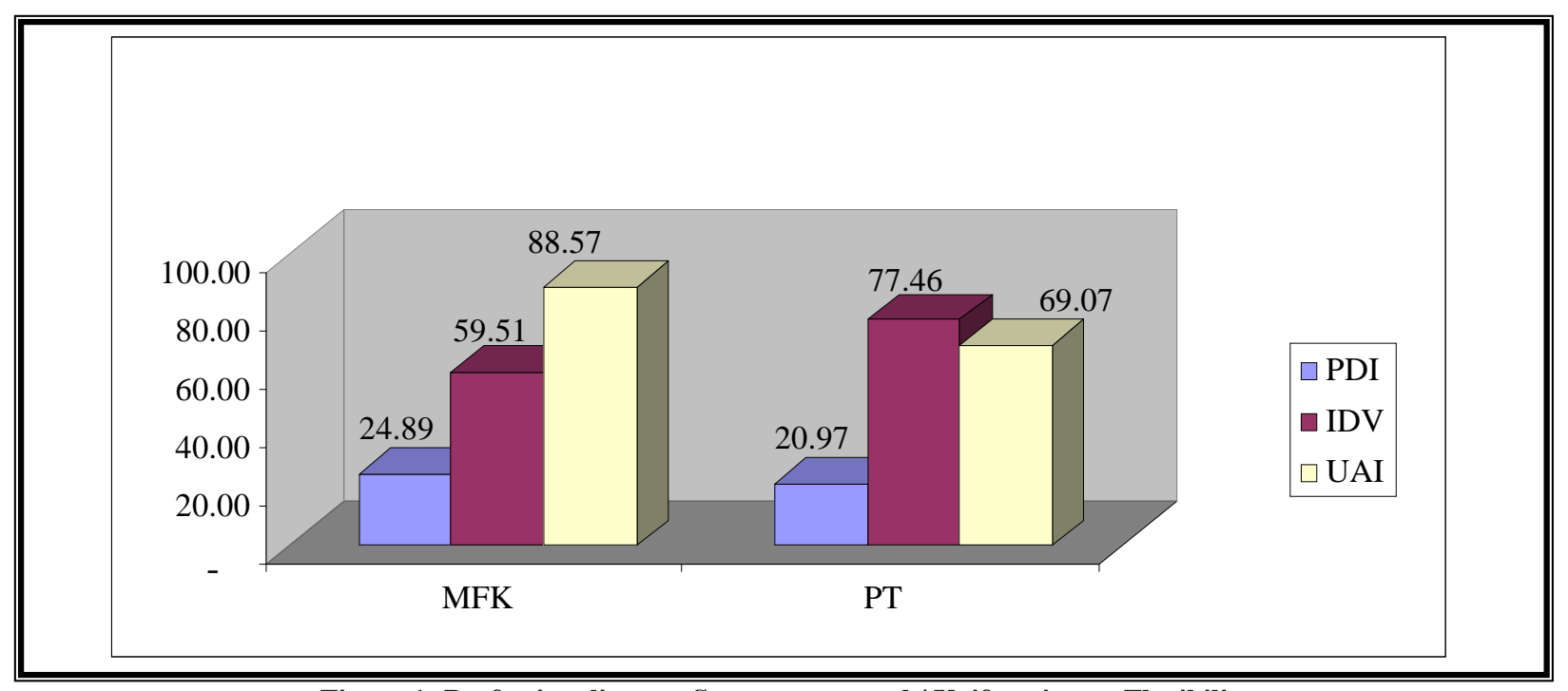

Figure 1: Professionalism vs. Statutory control / Uniformity vs. Flexibility

The results suggest that, due to a higher individualism ranking and lower uncertainty avoidance and power distance rankings, PTC (IDV of 77.46/UAI of 69.07/PDI of 20.97) will be leaning towards professional judgment while MFK (IDV of 59.51/UAI of $88.57 /$ PDI of 24.89) will rank high in terms of statutory control, which are indicative of a preference of prescriptive control. The empirical data also revealed that MFK will rank higher than PTC in terms of uniformity due to higher power distance and uncertainty avoidance rankings and lower individualism rankings. The participants from PTC may therefore be expected to be more flexible when applying accounting practices and principles.

\section{Conservatism versus optimism}

Gray's third hypothesis suggests that higher uncertainty avoidance (UAI) and lower individualism (IDV) and masculinity (MAS) are indications of a preference for conservatism. The results pertaining to cultural dimensions relevant to the accounting values of conservatism and optimism are set out in Figure 2 below. 1

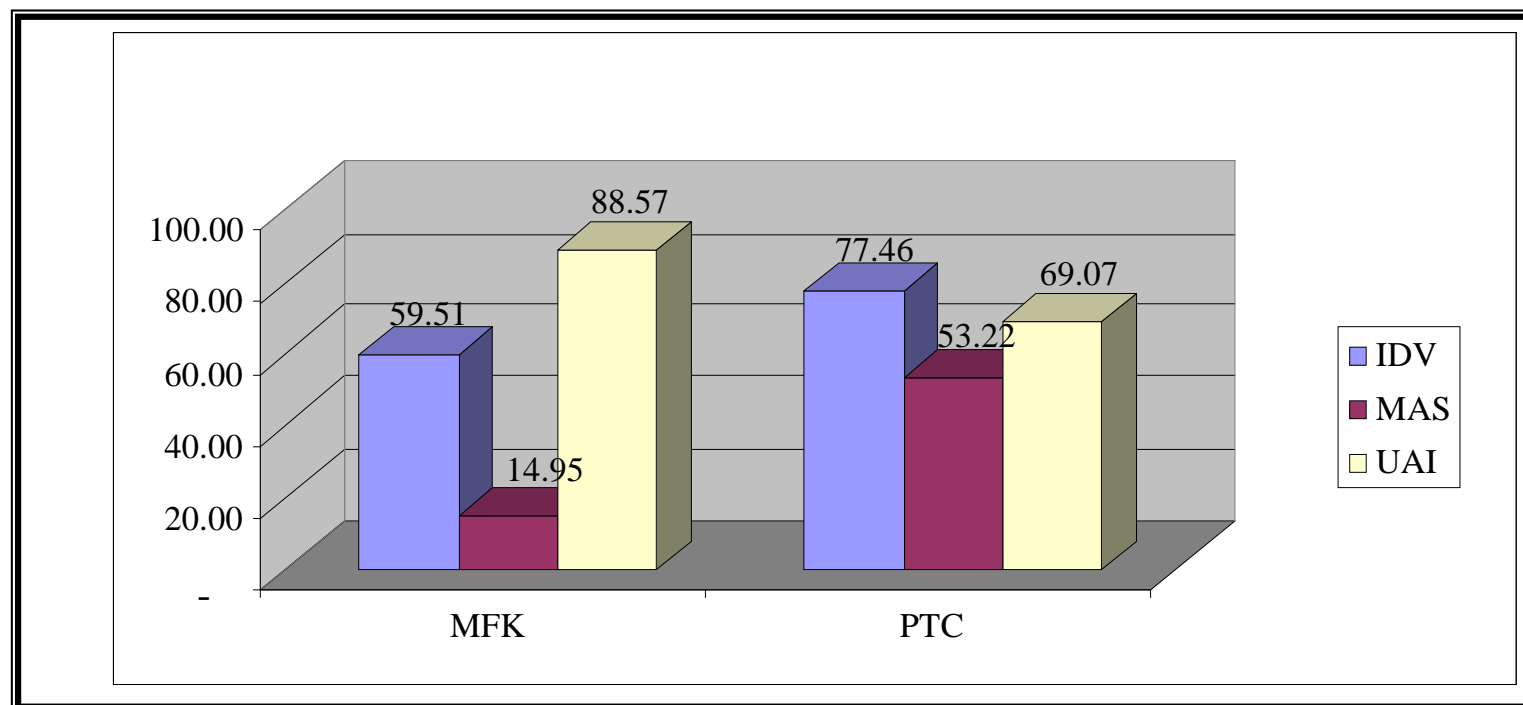

Figure 2: Conservatism vs. Optimism 
Higher uncertainty avoidance together with lower individualism and masculinity rankings at MFK (UAI of 88.57/IDV of 59.51/MAS of 14.95) will result in a higher conservatism ranking than at PTC (UAI of 69.07/IDV of 77.46/MAS of 53.22). Participants from the MFK campus should therefore be more cautious in their approach as opposed to a more optimistic and risk-taking approach at PTC.

\section{Secrecy versus Transparency}

Gray's fourth hypothesis suggests that a higher ranking in terms of uncertainty avoidance (UAI) and power distance (PDI) and a lower ranking in terms of individualism (IDV) and masculinity (MAS) is indicative of a preference for secrecy. The results pertaining to the cultural dimensions relevant to the accounting values of secrecy and transparency are set out in Figure 3 below.

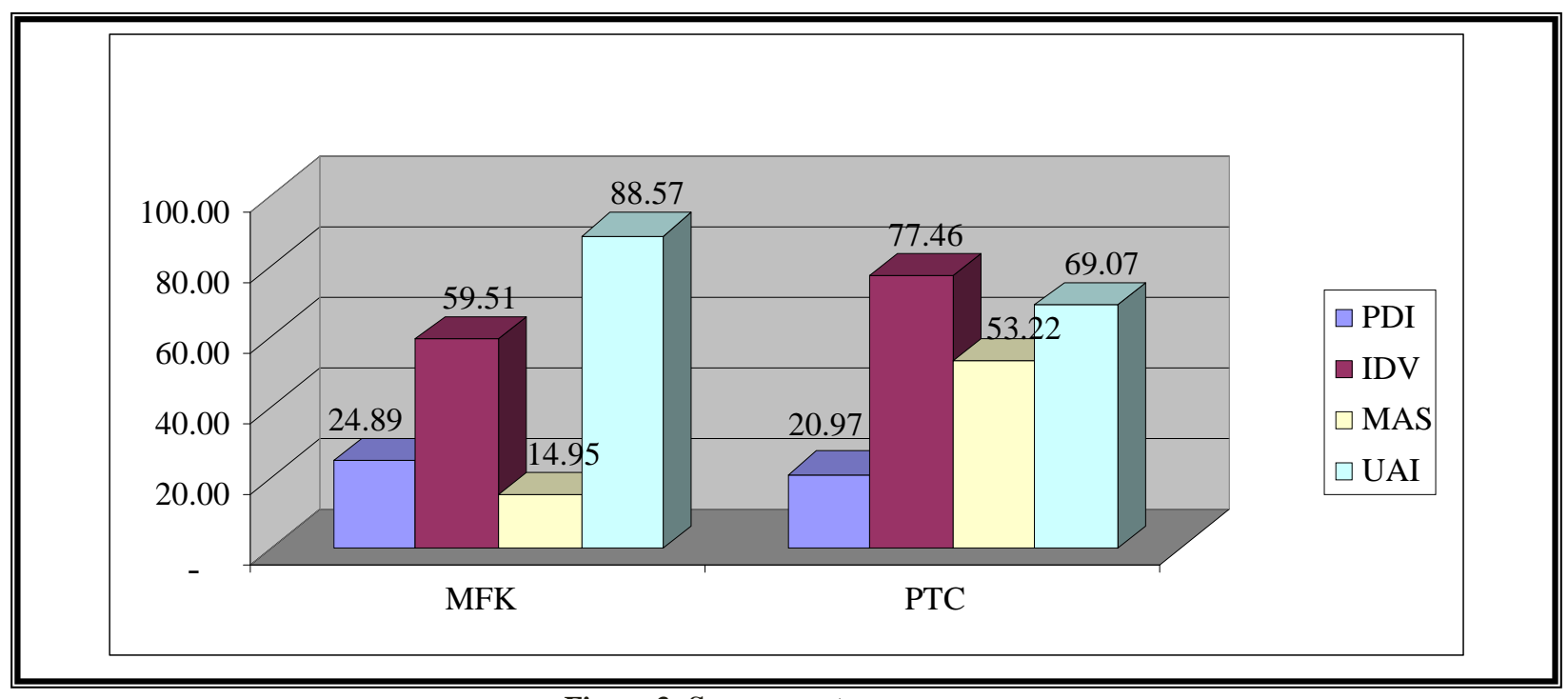

Figure 3: Secrecy vs. transparency

Higher uncertainty avoidance and power distance as well as lower individualism and masculinity rankings at MFK indicates that secrecy is more applicable to MFK (UAI of 88.57/PDI of 24.89/IDV of 59.51/MAS of 14.95). Participants from MFK should therefore be more cautious in their approaches to accountancy practices as opposed to a more optimistic and (perhaps) risk-taking approaches at PTC (UAI of 69.07/PDI of 20.97/IDV of 77.46/MAS of 53.22). They are also more likely to prefer confidentiality and the restriction of disclosure of information as opposed to the more transparent, open and publicly accountable approaches that may be expected from participants at the PTC campus.

\section{DISCUSSION}

Firstly, the evaluation of cultural dimensions of the two campuses as discussed in the first phase of the study revealed that masculinity at PTC appeared to be significantly higher than MFK. Qualities such as assertiveness, material success and advancement are considered to be more dominant at PTC. When considering the backgrounds of the two groups, it is evident that the participants from the PTC campus are predominantly white individuals. The high masculinity rating at PTC could therefore be indicative of the dominant nature and materialistic views of individuals from privileged apartheid-era backgrounds in South Africa. The cultural dimension relating to individualism at MFK was notably lower than PTC, which is indicative of the 'we' of a group of individuals. The results thus suggest that the focus at MFK would be more 'on the group' as opposed to 'on the individual'. It was also revealed that uncertainty avoidance at MFK was higher than at PTC, suggesting that deviations from norms may be punished in order to encourage conformity. It is therefore suggested, that based on 
the mentioned cultural dimensions, the concept of a uniform set of global accounting standards should be more acceptable by participants from the MFK environment due to a lower preference for individual rights or individual accounting scenarios and deviations from the accepted norms. The cultural dimension relating to power distance at PTC was lower than at MFK, and societies with low power distance ratings do not readily accept hierarchical orders and demand justification for power inequalities. MFK will therefore not necessarily question hierarchical orders and individuals will more easily accept their positions within the group.

Secondly, in respect of accounting values as considered in the second phase of the study, a key objective of IFRS is to meet the information needs of investors in the international capital markets. In order to meet such informational needs the adoption of IFRS, as a uniform global set of accounting standards, should result in meaningful and comparable financial data across borders. By means of inductive reasoning it is suggested that the following accounting values of Gray are required to adopt a uniform global set of accounting standards:

- $\quad$ Statutory control in order to adhere to a single set of prescribed rules and regulations in connection with accounting transactions and related disclosure thereof;

- Uniformity in order to, irrespective of different backgrounds, apply uniform accounting practices and principles;

- $\quad$ Conservatism in order to adapt a cautious approach when applying accounting practices and principles; and

- $\quad$ Transparency in order to be open and publicly accountable.

Based on the above, accounting values can be allocated to the two institutions included in this study. If ratings are allocated in units of 1 to 2 , where 2 represents a high preference for an accounting value and 1 is representative of a low preference for an accounting value, the following diagram can be compiled:

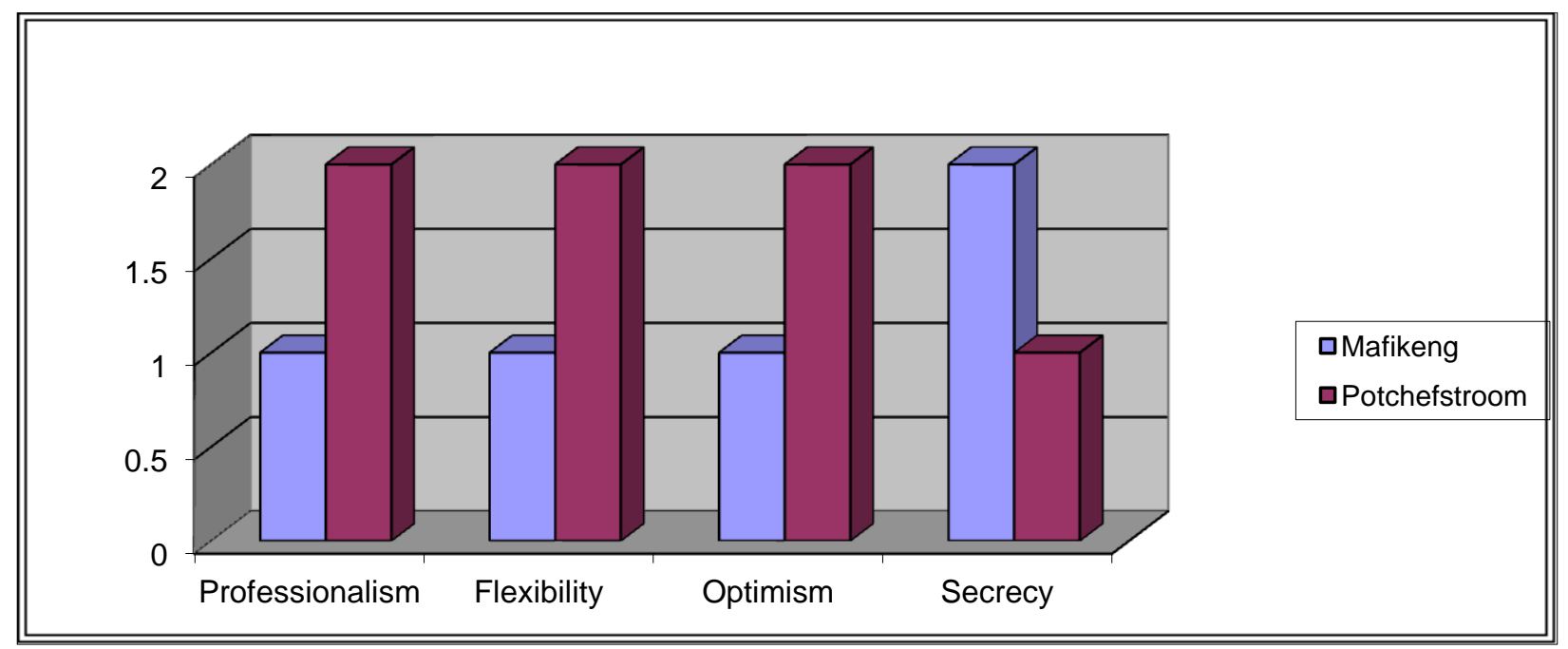

Figure 4: Accounting value ranking per institution

Furthermore, the accounting values of Gray as per the second phase of the study also revealed that MFK has the majority of the attributes (with the exception of secrecy) required to adopt a global set of accounting standards. The challenges facing participants from PTC are the accounting values of professionalism, flexibility and optimism. Lecturers at the PTC campus should therefore focus on these attributes as it is suggested that the opposite attributes, statutory control, uniformity and conservatism are required for the successful adoption of global set of accounting standards. In turn, lecturers at the MFK campus should focus on changing the mind-sets of accounting students from secrecy to a transparent approach when a global set of accounting standards is adopted. 


\section{CONCLUSION}

The adoption of IFRS should be acceptable to various groups on a global basis. It is suggested that societies with dominant individuals may tend to apply different rules to different scenarios, whereas societies with dominant groups should more readily accept the concept of a single requirement pertaining to all scenarios. As a result, if the impact of different cultural backgrounds of prospective accountants is considered against the background of the concept of a uniform set of accounting standards it is suggested that MFK has the majority of the cultural dimensions and accounting values considered necessary for the successful adoption of IFRS.

In answering the stated research question, it is clear from this research, that in the South African context with its wide diversity of cultures and peoples, that the accounting profession, including the application of IFRS, is open to 'cultural interpretation'. As such, it becomes an important factor to be cognizant of in the training and education of future accountants. The recommendations contained in this article are not only limited to accounting education. It may very well be argued that the individuals included in the survey are representative of other role players in the accounting environment as well. As human beings assign specific values to their own reality within a specific group of society it is suggested that practitioners, governing bodies and standard setters should also take note of the results and related recommendations when adopting the IFRS on a global basis.

\section{AUTHOR INFORMATION}

Professor Pieter W Buys is currently the Research Program Leader at the North-West University (South Africa) and holds two PhDs (Accountancy and Management Accountancy), two Masters Degrees (MComm and MBA), and he is also a US Certified Management Accountant (CMA). He has worked in the ERP and business consulting industry in Canada, the USA and South Africa for more than 15 years. He has published more than 28 articles in peer-reviewed and professional publications. His current research revolves around corporate social responsibility and corporate resilience. E-mail: pieter.buys@nwu.ac.za

Associate Professor Danie Schutte is currently Professor in the School of Accounting Sciences at the North-West University (South Africa) and holds a PhD in Financial Accountancy, a Masters degree in Taxation and is a Chartered Accountant (SA). He has taught extensively in the Financial Accountancy programs. His academic research output includes more than 10 peer - reviewed articles and conference presentations. His current research focuses on IFRS implementation in a SME context. E-mail: danie.schutte@ nwu.ac.za

\section{REFERENCES}

1. Askary, S. (2006). "Accounting professionalism - a cultural perspective of developing countries". Managerial Auditing Journal, 21(1):102-111.

2. Belkaoui, A.R. (1990). Judgement in International Accounting: A Theory of Cognition, Cultures, Language and Contracts. Westford, Conn: Greenwood Press.

3. Beukes, A. (2004). The first ten years of democracy, language policy in South Africa. http://www.linguapax.org/congres04/pdf/1 beukes.pdf. Accessed on November $25^{\text {th }}, 2009$.

4. Bloom, R. and Naciri, M.A. (1989). "Accounting Standard Setting and Culture: A Comparative Analysis of United States, Canada, England, West Germany, Australia, New Zealand, Sweden, Japan and Switzerland”. International Journal of Accounting Education and Research, 24(1):70-97.

5. Chari, P.S.V. and Narasimhan, P.S. (2001). "Accounting standards for banks need review". http://www.hindu.com/thehindu/2001/09/06/stories/0606000j.htm. Accessed on February $2^{\text {nd }}, 2009$.

6. $\quad$ Ernest\&Young. (2005). "Key differences and lessons learned". http://www.ey.com/KR/en/Issues/Governance-and-reporting/IFRS/IFRS Differences-and-lessons-learned. Accessed on September $24^{\text {th }}, 2009$.

7. $\quad$ FEI Canada see Financial Executives International Canada.

8. Financial Executives International Canada. (2007). "FEI Canada Calls for One Year Delay in IFRS Implementation”. http://www.feicanada.org/files/IFRSAcSOCNR_25OCT07_Final.pdf. Accessed on September $24^{\text {th }}, 2009$. 
9. Garcia-Sordo, J.B. and Baren, A.W. (1999). "National culture and preference for alternate accounting controls - USA vs Mexico". International Marketing Review, 16(4/5):314-325.

10. Gray, S.J. (1988). "Towards a Theory of Cultural Influence on the Development of Accounting Systems Internationally". Abacus, 24:1-15.

11. Gujarathi, M. (2008). "Sachiko Corporation: A Case in International Financial Statement Analysis". Issues in Accounting Education, 23(1):77-101.

12. HassabElnaby, H.R. Epps, R.W. and Said, A.A. (2003). "The Impact of Environmental Factors on Accounting Development: An Egyptian Longitudinal Study". Critical Perspectives on Accounting, 14(3):273-292.

13. Hofstede, G. (1980). Cultures Consequences: International Differences in Work Related Values. Beverly Hills, Calif: Sage Publications.

14. Hofstede, G. (1994). "Value Survey Model (VSM)". http://stuwww.uvt.nl/ csmeets/ 1st-VSM.html. Accessed on February $2^{\text {nd }}, 2009$.

15. Jaggi, B.L. (1975). "The Impact of the Cultural Environment on Financial Disclosures". The International Journal of Accounting, 10:75-84.

16. Kollaritsch, F.P. (1965). "International Accounting Practices". The Accounting Review, 40(2):382-385.

17. Lin, Z. and Wang, L. (2001). "Financial disclosure and accounting harmonization: cases of three listed companies in China". Managerial Auditing Journal, 16(5):263-273.

18. Lindahl, F. and Fanelli, R. (2002). "Applying continuous improvement in another culture”. Journal of Accounting Education, 20(4):285.

19. Marrero, J. and Brinker, T.M. (2007). “Are Accounting Standards Uniform? Recognizing Cultural Differences Underlying Global Accounting Standards”. Journal of Financial Service Professionals, 16-18, January.

20. McKinnon, J.L. (1986). The Historical Development of the Operational Form of Corporate Reporting Regulation in Japan. New York: Garland.

21. Moustafa, L.K. Slaubaugh, M. and Wang, H.C. (2008). "Cultural Effects on Accounting Practice and Investment Decisions". Proceedings of ASBBS, 15(1): 535-544.

22. Mueller, G. (1965). "Whys and Hows of International Accounting". The Accounting Review, 40(2):386.

23. Mueller, G. Gernon, H. and G. Meek, G. (1997). Accounting, An International Perspective, 4th edition. New York: Irwin/McGraw Hill.

24. Olimid, L. (2006). "An Empirical Study of the Accounting Values Shared By Romanian Accountants Aiming to Become Private Practitioners. Academy of Economic Studies Bucharest". http://papers.ssrn. com/sol3/papers.cfm?abstract_id=948953. Accessed on March 23 ${ }^{\text {rd }}, 2009$.

25. Perera, M.H.B. (1989). "Accounting in Developing Countries: A Case for Localised Uniformity". British Accounting Review, 21:141-158.

26. Radebaugh, L.H. (1997). International accounting and multinational enterprise, $4^{\text {th }}$ edition. New York: John Wiley \& Sons. 696 pages.

27. Salter, S.B. and Niswander, F. (1995). "Cultural Influence on the Development of Accounting Systems Internationally: A Test of Gray’s (1988) Theory”. Journal of International Business Studies, 26(2):379397.

28. Steffee, S. (2009). "IFRS discrepancies vary by country, company". http://www.entrepreneur.com/tradejournals/article/206051042.html. Accessed on September $24^{\text {th }}, 2009$.

29. Sudarwan, S. (1994). "The dynamic relationship between culture and accounting: An empirical examination of the Indonesian setting". http://www.ohiolink.edu/etd/sendpdf.cgi/Sudarwan\%20Sudarwan.pdf?acc num=case1057949264. Accessed on March 22 $2^{\text {nd }}, 2009$.

30. Sullivan, C.A. (2006). "Study of Cultural Issues related to Today's Accounting Students". http://www.asbbs.org/files/2006/ASBBS\%20EJournal\%202006\%20HTM\%20Files/a\%20study \%20of\%20cultural\%20asbbs\%20e-journal\%202006.pdf. Accessed on January $1^{\text {st }}, 2009$.

31. Tsakumis, G.T. Campbell, D.R. and Doupnik, T.S. (2009). "IFRS: Beyond the Standards". Journal of Accountancy, 207(2): 34 - 39.

32. Verma, S. (2000). "Culture and Politics in International Accounting: An Exploratory Framework". http://opensigle.inist.fr/handle/10068/583198. Accessed on June $24^{\text {th }}, 2009$. 
33. Violet, W.J. (1983). "The Development of International Accounting Standards: An Anthropological Perspective". The International Journal of Accounting Education and Research, 1-12, Spring.

34. WEBCPA. (2009). "Accounting Professors Urge IFRS Education". http://www.webcpa.com/news/Accounting-Professors-Urge-IFRS-Education-51825-1.html. Accessed on September $25^{\text {th }}, 2009$.

35. Willett, R. (2002). “An Empirical Assessment of Gray’s Accounting Value Constructs”. http://www.bus.qut.edu.au/faculty/schools/accountancy/documents/2002-003Willett.pdf.

36. Xiao, Z. Weetman, P. and Sun, M. (2004). "Political Influence and Coexistence of a Uniform Accounting System and Accounting Standards: Recent Developments in China". Abacus, 40(2):193-218. 